\title{
Towards sustainable neighbourhoods: a new handbook and its application
}

\author{
A.-F. Marique \& J. Teller \\ Local Environment: Management and Analysis (LEMA), \\ Research Centre on Territorial, Urban and Rural Sciences, \\ University of Liege, Belgium
}

\begin{abstract}
This paper presents a practical handbook that aims at helping local authorities and private developers to build and assess "sustainable neighbourhoods" in Wallonia (Belgium). This handbook was developed by the Research Centre on Territorial, Urban and Rural Sciences (Lepur, University of Liège), at the request of the Walloon Minister of the Environment, Spatial Planning and Mobility. The concrete aim of the handbook is to concretely define the concept of "sustainable neighbourhood" by clearly tagging the minimum criteria that a real estate project must meet to obtain the "sustainable neighbourhood" label in Wallonia. It is a tool for decision support in the design as well as the evaluation of real estate projects, since the early stages of their design. The handbook is structured into 5 main themes and 25 criteria of sustainability. In a broad vision of sustainability, this handbook is not strictly limited to energy issues but considers "sustainability" in all its multiple components: location, network connection, mobility of inhabitants, use of natural resources, landscaping, waste management, diversity of function, social interactions, among others. The handbook is firstly presented and, then, applied to 12 recent case studies in order to identify common invariants in the design process of "sustainable neighbourhoods" and barriers to the integration of cross-cutting principles of sustainability in neighbourhood projects. Our main results namely show that the criteria dealing with energy performance of buildings and green spaces have percolated in many cases. However, the diversity of housing types, the accessibility to handicapped peoples, social diversity and participation issues remain poorly addressed in most of the cases studies.

Keywords: sustainable neighbourhood, sustainability, handbook, decision support tool, urban projects, urban design, evaluation, local actors, case study.
\end{abstract}




\section{Introduction}

Several urban neighbourhoods, built or retrofitted from the 90s, mainly in northern Europe, have become renowned for their sustainability. They were widely praised as best practices in terms of "sustainable urban planning" and "sustainable architecture". Amongst the most renowned projects, Vauban in Fribourg (Germany), BO01 and Augustenborg in Malmö (Sweden), BedZed in Sutton (The United Kingdom), Kronsberg in Hanover (Germany) or Hammarby Sjöstad in Stockholm (Sweden) are often highlighted. These exemplary neighbourhoods have received a great deal of media coverage but were produced under exceptional conditions that are difficult to reproduce in other urban projects: e.g., the carriage by public authorities, the numerous dispensations needed to build these neighbourhoods, the significant public subsidies they have benefited to fund the overinvestment [2-4]. Developed with a view to innovation and competition between European cities, these sustainable neighbourhoods had a strong technical connotation. They were almost exclusively dedicated to the sole environmental pillar of sustainable development (development of low energy housing, use of various renewable energies, reduction in water uses, waste management, etc.) and neglected social and economic aspects (lack of social diversity, dwellings mainly dedicated to rich households, etc.).

After this first phase of experimentation and maturation, the principles of sustainability, including social and economic aspects, have more been widely included in the development of sustainable neighbourhoods. The concept of "sustainable neighbourhood" is being democratized and grows in popularity. As highlighted by Da Cunha [5], the first pilot experiments have allowed to pave the city to new concerns. In the same vein, several neighbourhood sustainability assessment tools have recently been developed [6] to help to design, assess or label sustainable neighbourhoods even if the topic of sustainability assessment of neighbourhoods remains less developed and need to continue to evolve et to be strengthen [6-8]. Well-known examples of these neighbourhood sustainability assessment tools are, amongst others, the STAR Community Rating System (Sustainability Tools for Assessing and Rating Communities) [9] and the US Green Building Council's LEED-ND (Leadership in Energy and Environmental Design - Neighbourhood Development) [10] in the United States, BREEAM Communities (BRE Environmental Assessment Method) in the United Kingdom [11], HQE2R (Haute Qualité Environnementale et Economique dans la Réhabilitation des bâtiments et le Renouvellement des Quartiers) [12] in France and CASBEE (Comprehensive Assessment System for Built Environment Efficiency - Urban environment) [13] in Japan. These tools aim to assess and rate communities and neighbourhoods against a set of defined criteria and themes. They propose a checklist of criteria (mainly optional) and a range of various guidelines to help local stakeholders, designers and citizens move towards more sustainability but are not often adapted to local specificities.

In this context, this paper presents a novel handbook developed to help designers, architects and private developers to build new sustainable neighbourhoods in Wallonia (the French-speaking part of Belgium) but also 
regional and local authorities to assess urban projects, at the neighbourhood scale. This handbook has been developed by the Research Centre on Territorial, Urban and Rural Sciences (Lepur) of the University of Liège, at the request of the Walloon Minister of the Environment, Spatial Planning and Mobility. This handbook was published $(2,500$ paper pieces + pdf to download on the website of the Walloon government; http://www.wallonie.be/fr/publications/quartiersdurables-mode-demploi) in February 2014. The handbook is currently used in several concrete projects and is becoming the reference to build and assess sustainable neighbourhood in Wallonia. This handbook is presented in Section 2. In Section 3, the settings grid of the handbook is applied to 12 local case studies to understand how principles of sustainable urban planning are taken into account by private developers, architects and local authorities, when developing new urban projects, at the neighbourhood scale and to highlight the main common characteristics of these projects, the main brakes that occur and best practice to reproduce. Finally, Section 4 summarizes the main findings of this application and proposes general guidelines to inform and facilitate the integration of sustainability criteria in a growing number of urban projects, at the neighbourhood scale.

\section{Presentation of the handbook}

\subsection{General aims of the handbook and context in which it was developed}

The handbook, called "Référentiel quartiers durables" (in French) is a general framework that aims at initiating and favouring the emergence and the development of "sustainable neighbourhoods" in Wallonia. This handbook is addressed to operational actors of urban planning and architecture (private developers, architects, urban planners, funders, local and regional authorities). This work is inscribed in the framework of the 2009-2014 governmental program that proposed to support topical initiatives in this domain. This handbook aims at concretely defining the concept of "sustainable neighbourhood" by clearly tagging the minimum criteria that a real estate project must meet to obtain the "sustainable neighbourhood" label in Wallonia. It is a tool for decision support in the design stage as well as for the evaluation of real estate projects, since the early stages of their design. Although all new neighbourhoods are not intended to enter into this process, integrating cross-cutting sustainability criteria in a great number of urban projects is a major societal issue. That is why the handbook proposes clear, simple and measurable cross-cutting objectives of sustainability that can be used in every urban project.

This handbook is intended to accompany sustainable neighbourhoods' projects, from the design phase. He can be used in different legal procedures for the urbanization of neighbourhoods in Wallonia (such as urbanization permits, permits for group housing, urban and environmental reports, urban remembrement processes) but also in architectural competitions and call for projects. Also note that this handbook is specifically dedicated to the production of new neighbourhoods. The retrofitting of existing neighbourhoods is another major 
challenge that comprises specific issues. Another handbook dedicated to the retrofitting of existing neighbourhoods should be soon developed to ensure the coherence of the whole process.

More concretely, this handbook is articulated around 5 main cross-cutting themes and 25 cross-cutting criteria of sustainability to inscribe an urban project in a global vision of sustainability. In a broad vision of sustainability, this handbook is not strictly limited to energy issues but considers "sustainability" in all its multiple components: location, network connection, mobility of inhabitants, use of natural resources, landscaping, waste management, diversity of function, social interactions, among others.

A quantitative value is attributed to each criterion. These values are adapted according to the location of the neighbourhood/projects inside or outside urban poles, city centres and villages (as defined in the Development Scheme of the Regional Territory (SDER)). These values can be strengthen by the local / regional authorities, the private developer or the architects if needed, in accordance with the local potentialities of each site and each projects.

The 25 proposed criteria are simple to calculate and to evaluate. They are concrete and objectivable in order to facilitate their appropriation by all the actors involved in the development of urban projects. Each criterion is clearly illustrated by schemes and examples in the handbook (see Figure 1 for an example). The handbook also allows to secure and to padlock several main criteria of sustainability that have a huge impact on the cost of development and on environmental and social aspects (the built density, the urban form (common ownership), the development of green spaces, the links between the neighbourhood and its surrounding and the diversity of dwellings), from the conception of the neighbourhood. These main criteria are defined as "necessary criteria" and must be completed to gain the "sustainable neighbourhood" label in Wallonia (see also Section 2.6, below).

Another specificity of this handbook is that criterion are mainly oriented towards urban planning rather than towards the individual building scale, in order to favour an integrated approach that namely focus on collective initiatives and equipment, inside and outside the new neighbourhood as well as the potentialities of its surrounding (public transportation, proximity of shops, services, green spaces, etc.). The duration to perform the assessment of a neighbourhood is limited to maximum two days. The handbook was validated by the Minister and is available since February 2014. The handbook is actually used in several projects where the proposed criteria are included in specification sheets or in the description of architectural competitions.

\subsection{Theme 1: potentialities of the location and of the project}

The first cross-cutting theme of sustainability is dedicated to the potentialities of the location and the urban project.

Criterion A1-Train services: The site in which the neighbourhood will be developed is located at maximum 1,500 meters of a regional train station/ maximum 1,000 meters of a local train station. 
Criterion A2-Bus services: There are at least 34 buses by day in the surrounding of the neighbourhood (the assessment takes place in an area of 700 meters around the boundary of the considered site) in urban poles and city centres. In villages, there are at least 20 buses in the considered area.

Criterion A3-Diversity of functions: There are at least 15 functions, representing at least 3 of the 5 main categories (large shops, shops, services, public services, equipment and leisure) in the surrounding of the neighbourhood (the assessment takes place in an area of 700 meters around the boundary of the considered site) in urban cores and city centres. There are at least 5 functions, representing at least 3 of the 5 main categories in villages.

Criterion A4-School: There is at least one school in the surrounding of the neighbourhood (the assessment takes place in an area of 700 meters around the boundary of the considered site).

Criteria A5-Built density: The net built density of the neighbourhood is worth, at least, 40 dwellings per hectare in urban poles, 30 dwellings per hectare in city centres and 20 dwellings per hectare in villages (these definitions come from the Development Scheme of the Regional Territory (SDER)).

The five criteria of the first theme aim at ensuring that the location in which the urban project will be developed, inside or outside a pole, offers enough opportunity to reduce travelled distances, to favour public transportation, etc. The

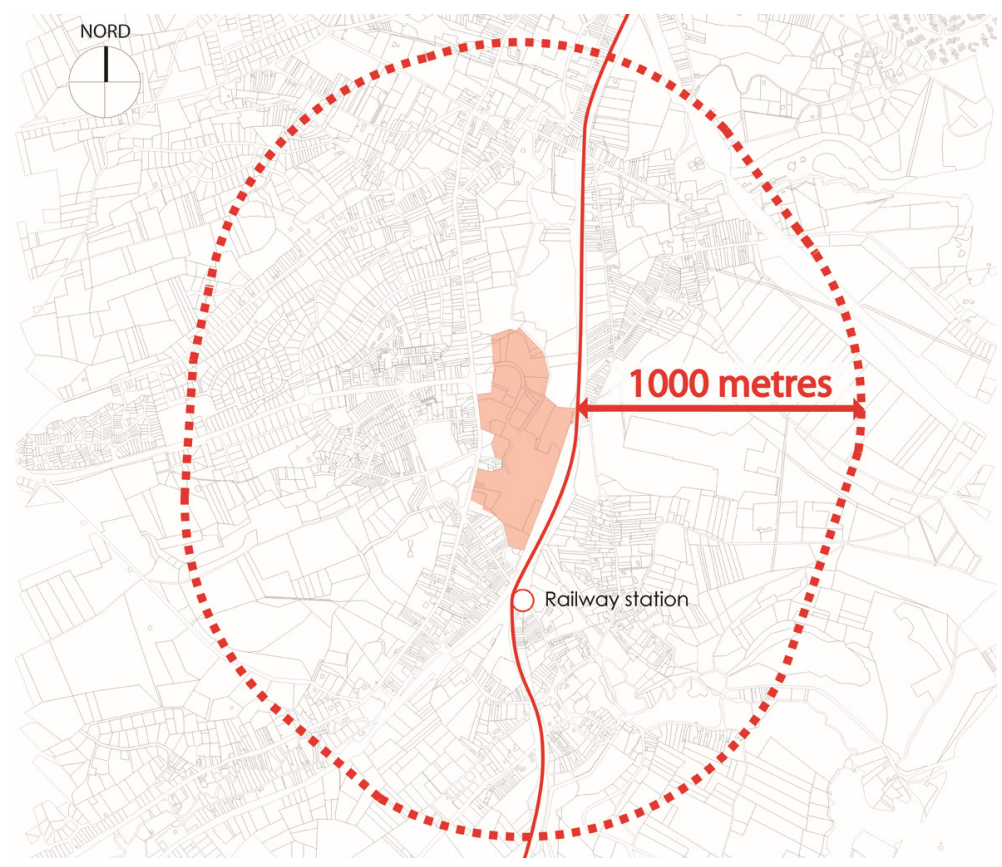

Figure 1: Example of illustrations included in the handbook (criterion A1-Train services). 
diversity of functions and uses is also important to improve the quality of life in neighbourhoods, during the day and the night.

The built density of the urban project is also considered in this first theme. We choose to use a net built density (that is to say that collective and public areas are not considered in the reference area, in order to avoid the privatization of the neighbourhood). The value adopted in the handbook can be considered as low for an international audience but is based on the local situation in Wallonia, where numerous very low-density (5 to 12 dwellings per hectare) suburban neighbourhoods have been built in discontinuity to urban cores $[13,14]$.

\subsection{Theme 2: use of resources}

The second theme of the handbook is dedicated to the use of resources. Beyond issues related to mobility and location, the development of sustainable neighbourhoods is also a relevant response to actual energetic and environmental challenges. Sustainable neighbourhoods are seen as an opportunity to limit the use of energy, namely by favouring more compact urban forms and a good access to light and sun, from the design of the urban project.

Criterion B6-Common ownership: At least $50 \%$ of the dwellings are terraced dwellings in urban cores and city centres. At least $30 \%$ of the dwellings are terraced dwellings in villages.

Criterion B7-Access to sun and light: This criterion is assessed by drawing a horizontal line, at 2 metres from the ground, on each facade of the neighbourhood. A second line, making an angle of $25^{\circ}$ with the first one is then drawn and must not intercept any other building. At least $60 \%$ of the facades of the neighbourhood respect this criterion in urban cores and city centres. At least $75 \%$ of the facades of the neighbourhood respect this criterion in villages.

Criterion B8-Heating requirements and energy: The current thermal regulation is respected. At least one building has better performances than the regulation.

Criterion B9-Heating requirements and energy: A specification sheet, specifying the conditions to respect and proposing a program to control the quality of the construction is develop. The constructors and developers that will build the neighbourhood must adhere to this specification sheet.

Criterion B10-Materials: There is a general balance between cuttings and embankments. A specification sheet specifies the origin and characteristics of the materials that will be used. The reversibility of the developments inside and outside buildings (public spaces, parking lots, etc.) is encouraged.

\subsection{Theme 3: green spaces}

The third theme of the handbook is dedicated to green spaces. Green spaces are particularly important because they improve the quality of life within cities. They also participate to the regulation of humidity and temperature, etc.

Criterion C11-Soil sealing: Permeable surfaces represent at least $30 \%$ of the total surface area of the site on which the neighbourhood is developed. 
Criterion C12-Rain water: Rain water and used water are collected separately, if a natural exit is available (river, lake, etc.). If not, the retention and infiltration of rain water, in situ, is favoured via the use of adequate equipment.

Criterion C13-Green spaces: If the surface area of green and blue spaces located in an area of 700 meters around the site is lower to $2,000 \mathrm{~m}^{2}$, green and blue spaces must be developed in the project. Their surface area is worth $30 \%$, at least, of the surface area of the neighbourhood.

Criterion C14-Plants and biodiversity: Only local plants are used. 2 different types of plants (grass, flower beds, bushes, isolated trees, groups of trees) are used in urban cores and city centres; 3 in villages.

\subsection{Theme 4: amenities of the neighbourhood}

The fourth theme of the handbook is dedicated to the amenities in the new neighbourhood. The focus id put on collective initiatives and equipement, at the neighbourhood scale. The quality of architecture and the appropriation of private spaces are also addressed in this theme.

Criterion D15-Roads and links with the surroundings: "cul-de-sac" roads represent less than $20 \%$ of the roads developed in the neighbourhood. Links with existing roads are favoured.

Criterion D16-Parking (car and bicycles): The number of parking places must be negotiated with the local authorities (depending on the local regulation) and specify in a specification sheet. Each dwelling comprises at least one parking place for bicycle (inside the dwelling or in a common room).

Criterion D17- Architecture and image of the neighbourhood: A specification sheet presenting the architectural options for the neighbourhood is proposed by the architects and urban planners. This document also specifies the integration of the project into its built and natural environments.

Criterion D18-Appropriation of private spaces: Each dwelling comprises an external space (garden, terrace, balcony). The minimum surface area of the external space is worth $6 \mathrm{~m}^{2}$ per dwelling. Necessary measures are undertaken to ensure the privacy of these external spaces.

Criterion D19-Collective equipment: At least two collective equipment are proposed in the neighbourhood (e.g., shared garden, games for children).

Criterion D20-Waste management: Infrastructures to favour the collection, grouping and sorting of waste are developed. The collection of food and garden wastes, and their re-use in the neighbourhood, are particularly encouraged.

\subsection{Theme 5: social aspects and public participation}

The last theme of the handbook is dedicated to the diversity of uses and dwellings within the neighbourhood, the accessibility to different kinds of people and community involvement.

Criterion E21-Diversity of uses: At least one new function (shop, service, etc.) is proposed in the neighbourhood, in complementarity with the offer existing in the surrounding. 
Criterion E22-Diversity of dwellings: The neighbourhood comprises at least $10 \%$ of studio/ " 1 bedroom" apartment, $10 \%$ of " 2 bedrooms" dwellings and $10 \%$ of "3 and more bedrooms" dwellings. The type of the remaining dwellings is defined, in collaboration with local authorities.

Criterion E23-Social housing: At least 10\% of the dwellings are accessible to lowincome households.

Criterion E24-Access to handicapped people: At least 10\% of the dwelling are accessible to handicapped people, or are transformable to allow the accessibility of handicapped people in the future. Public and collective spaces are accessible to handicapped people.

Criterion E25-Community involvement: A specification sheet presenting the actions that will be undertaken to favour the community involvement of neighbours and future inhabitants is proposed. At least, one public meeting is organized to present and discuss the project.

\subsection{Conditions to inscribe an urban project in a sustainability perspective}

To gain the "sustainable neighbourhood" label in Wallonia, 20 criteria (out of the 25 criteria proposed in the handbook) must be met. The choice of the 20 criteria is up to the developers, funders and architects and allows to give a particular "colour" to each project, according to the local specificities and interests of the stakeholders. Moreover, 2 of the 3 first criteria (A1-A3) as well as criteria A5 (built density), B6 (common ownership), C13 (green spaces), D15 (roads and links with the surroundings) and E22 (diversity of dwellings) are considered as primary criteria. They are particularly important, in a global view of sustainability. If not met, the urban project is not considered as a "sustainable neighbourhood".

\section{Cross analysis of 12 case studies}

\subsection{Presentation of the case studies}

The settings grid proposed in the handbook was applied to 12 case studies, prior to its validation and publication. The aim of this application was to test the applicability of the criteria and their relevance to assess the sustainability of urban projects, at the neighbourhood scale. The selected case studies are local urban projects (in Belgium) and were selected to cover a wide range of projects (e.g. projects developed, under development or under progress; location in urban centres, in suburbs, in rural areas; architectural competition, urban remembrement, etc.; public or private projects). The main characteristics of the 12 case studies are summarized in Table 1. Data were collected in August and September 2013. Interviews with stakeholders were conducted to complement the written documents (plans, specification sheets, etc.).

\subsection{Main results and key lessons}

The location of the 12 case studies is good. Criteria A1 to A4 are met in 6 projects. In the 6 remaining projects, distance to train station is high but is compensated by 
Table 1: Main characteristics of the case studies.

\begin{tabular}{|c|c|c|c|c|c|c|}
\hline ID & Location & Progress & Funding & $\begin{array}{c}\text { Total S } \\
\text { area (ha) }\end{array}$ & $\begin{array}{c}\text { Net S } \\
\text { area (ha) }\end{array}$ & $\begin{array}{c}\text { Nb of } \\
\text { dwellings }\end{array}$ \\
\hline P1 & Urban & Built & Private & 0.76 & 0.52 & 75 \\
\hline P2 & Urban & Built & Public-private & 2.16 & 1.54 & 239 \\
\hline P3 & HP & In progress & Private & 5.32 & 2.30 & $150-170$ \\
\hline P4 & Urban & In progress & Private & 14 & 10. & 220 \\
\hline P5 & Urban & In progress & Private & 2 & 0.77 & 60 \\
\hline P6 & Urban & Study & Private & 2.85 & 1.29 & 97 \\
\hline P7 & Urban & In progress & Private & 2.30 & 1.36 & 80 \\
\hline P8 & Urban & Study & Public & 2.89 & 1.64 & 175 \\
\hline P9 & HP & Study & Public & 30 & 7.60 & 800 \\
\hline P10 & HP & Study & Public & 6.55 & 3.09 & 78 \\
\hline P11 & Urban & Built & Public & 1.1 & 0.5 & 22 \\
\hline P12 & Urban & Built & Public-private & 8.6 & 2.2 & 345 \\
\hline
\end{tabular}

good bus services and a huge diversity of functions in the surroundings of the neighbourhoods. However, the built density of the studied projects remains low in several cases (especially in cases 4 and 10 where the built density is lower than 25 dwellings per hectare). In case 5, the initial density of the project (as well as its thermal performances, the diversity of uses, etc.) was progressively reduced because funders finally did not want to develop an urban project too ambitious, or at least too different from what they use to develop (low-density residential neighbourhood). This trend to reduce the built density during the process was also highlighted in several other projects. The net surface area of the case studies varies between $30 \%$ of the total surface area in two neighbourhoods made up collective dwellings (9 and 12) and $75 \%$ in case study 4 , mainly made up individual semidetached houses.

The correlation between the total surface area of the case studies and the number of dwellings is high $\left(\mathrm{R}^{2}=0.83\right)$ whereas the correlation between the net built density and the number of dwellings is weak $\left(\mathrm{R}^{2}=0.38\right)$.

The thermal performances of buildings are often better than the requirements of the current regulation (case studies $2-9,12$ ) mainly because of the insulation of buildings. Only 6 projects (case studies 2-7) use renewable energies for heating, domestic hot water and/or the production of electricity. The selected case studies are mainly made up terraced houses, which allow to reduce energy needs for heating. This criterion is not met in 3 cases (1, 4 and 11). Life cycle assessment and embodied energy are not taken into account in the case studies. Moreover, the monitoring of the performance during the life of the neighbourhoods is never proposed although this was one of the main defaults of pioneer sustainable neighbourhoods [3].

The four criteria related to green spaces are met in most case studies. Permeable surfaces represent more than $30 \%$ of the area of the case studies, excepted in case 1 that was developed in a very dense city centre. The collection of rain waters and their infiltration in situ are often proposed $(2,3,5,6,10-12)$.

Although not imposed in the handbook (because of the presence of enough green spaces in the surroundings of the case studies), 6 projects $(3-7,12)$ propose to develop green spaces within the boundary of the neighbourhoods. 
Table 2: Synthesis of the analysis of the 12 case studies $(1=$ criterion met, $0=$ criterion not met, $-=$ criterion not assessed; primary criteria are in black).

\begin{tabular}{|c|c|c|c|c|c|c|c|c|c|c|c|c|}
\hline & P1 & P2 & P3 & P4 & P5 & P6 & P7 & P8 & P9 & P10 & P11 & P12 \\
\hline A1 & $\mathbf{1}$ & $\mathbf{1}$ & $\mathbf{0}$ & $\mathbf{1}$ & $\mathbf{0}$ & $\mathbf{0}$ & $\mathbf{0}$ & $\mathbf{1}$ & $\mathbf{0}$ & $\mathbf{0}$ & $\mathbf{1}$ & $\mathbf{1}$ \\
\hline A2 & $\mathbf{1}$ & $\mathbf{1}$ & $\mathbf{1}$ & $\mathbf{1}$ & $\mathbf{1}$ & $\mathbf{1}$ & $\mathbf{1}$ & $\mathbf{1}$ & $\mathbf{1}$ & $\mathbf{1}$ & $\mathbf{1}$ & $\mathbf{1}$ \\
\hline A3 & $\mathbf{1}$ & $\mathbf{1}$ & $\mathbf{1}$ & $\mathbf{1}$ & $\mathbf{1}$ & $\mathbf{1}$ & $\mathbf{1}$ & $\mathbf{1}$ & $\mathbf{1}$ & $\mathbf{1}$ & $\mathbf{1}$ & $\mathbf{1}$ \\
\hline A4 & 1 & 1 & 1 & 1 & 1 & 1 & 1 & 1 & 1 & 1 & 1 & 1 \\
\hline A5 & $\mathbf{1}$ & $\mathbf{1}$ & $\mathbf{1}$ & $\mathbf{0}$ & $\mathbf{0}$ & $\mathbf{1}$ & $\mathbf{1}$ & $\mathbf{1}$ & $\mathbf{1}$ & $\mathbf{0}$ & $\mathbf{0}$ & $\mathbf{1}$ \\
\hline \hline B6 & $\mathbf{0}$ & $\mathbf{1}$ & $\mathbf{1}$ & $\mathbf{0}$ & $\mathbf{1}$ & $\mathbf{1}$ & $\mathbf{1}$ & $\mathbf{1}$ & - & - & $\mathbf{0}$ & $\mathbf{1}$ \\
\hline B7 & 0 & 1 & 1 & 1 & 1 & 1 & 1 & - & 1 & - & - & 1 \\
\hline B8 & 0 & 1 & 1 & 1 & 1 & 1 & 1 & - & 1 & - & - & 0 \\
\hline B9 & 0 & 1 & 1 & 1 & 1 & 1 & 1 & - & - & - & 0 & 0 \\
\hline B10 & - & 1 & 1 & - & - & - & - & - & - & - & - & - \\
\hline \hline C11 & 0 & 1 & 1 & 1 & 1 & 1 & 1 & 1 & 1 & 1 & 1 & 1 \\
\hline C12 & 0 & 1 & 1 & 1 & 1 & 1 & 1 & 1 & 1 & 1 & 0 & 1 \\
\hline C13 & $\mathbf{1}$ & $\mathbf{1}$ & $\mathbf{1}$ & $\mathbf{1}$ & $\mathbf{1}$ & $\mathbf{1}$ & $\mathbf{1}$ & $\mathbf{1}$ & $\mathbf{1}$ & $\mathbf{1}$ & $\mathbf{1}$ & $\mathbf{1}$ \\
\hline C14 & 1 & 1 & 1 & 1 & 1 & 1 & 1 & 1 & - & - & 1 & 1 \\
\hline \hline D15 & $\mathbf{1}$ & $\mathbf{1}$ & $\mathbf{1}$ & $\mathbf{1}$ & $\mathbf{0}$ & $\mathbf{1}$ & $\mathbf{1}$ & $\mathbf{1}$ & $\mathbf{1}$ & $\mathbf{0}$ & $\mathbf{1}$ & $\mathbf{1}$ \\
\hline D16 & 1 & 1 & 1 & 1 & 0 & 1 & 1 & 1 & 1 & - & 1 & 0 \\
\hline D17 & 1 & 1 & 1 & 1 & 0 & 1 & 1 & - & - & - & 1 & 1 \\
\hline D18 & 1 & 0 & 1 & 1 & 1 & 1 & 1 & 0 & - & - & 1 & 0 \\
\hline D19 & 0 & 1 & 1 & 1 & 1 & 1 & 1 & 0 & 1 & 1 & 0 & 1 \\
\hline D20 & 0 & 1 & 1 & 0 & 0 & 1 & 1 & 0 & 1 & - & 0 & 1 \\
\hline \hline E21 & 0 & 1 & 1 & 0 & 1 & 1 & 1 & 1 & 1 & 0 & 1 & 1 \\
\hline E22 & $\mathbf{1}$ & $\mathbf{1}$ & $\mathbf{1}$ & $\mathbf{0}$ & $\mathbf{0}$ & $\mathbf{1}$ & $\mathbf{1}$ & $\mathbf{1}$ & - & - & $\mathbf{1}$ & $\mathbf{1}$ \\
\hline E23 & 0 & 1 & 1 & 1 & 0 & 0 & 0 & 1 & 1 & - & 1 & 1 \\
\hline E24 & 0 & 1 & 1 & 0 & 0 & 0 & 0 & 0 & - & - & 0 & 1 \\
\hline E25 & 0 & 0 & 1 & 0 & 0 & 1 & 0 & 0 & - & - & 1 & 0 \\
\hline \hline OK & 12 & 22 & 24 & 17 & 14 & 21 & 20 & 16 & 14 & 8 & 16 & 20 \\
\hline KO & 12 & 3 & 1 & 7 & 10 & 3 & 4 & 5 & 2 & 4 & 7 & 4 \\
\hline- & 1 & 0 & 0 & 1 & 1 & 1 & 1 & 4 & 9 & 13 & 2 & 1 \\
\hline \hline Final & KO & OK & OK & KO & KO & OK & OK & KO & OK & KO & KO & OK \\
\hline & & & & & & & & & & &
\end{tabular}

The percentage of "cul-de-sac" roads is especially high in cases 5 and 10 where developers wanted to keep some invariants of the traditional low-density neighbourhood. The number of parking places for cars is always high (more than 1 place per dwellings). This high rate of parking places is imposed by local authorities who want to avoid new inhabitants to park their car in existing neighbourhoods, although public transportation are widely available in the case studies. Parking places for bicycles are often limited to a common room.

Three projects $(2,8$ and 12$)$ are mainly made up collective buildings and several dwellings do not have a private external space. Collective equipment (especially shared gardens, games for children or a common room) are proposed in 9 case studies.

The waste management is often limited to the organization of a shared compost to collect and reuse food and garden wastes.

Three projects are only made up residential dwellings (1, 4 and 10). In the other case studies, proximity functions are proposed: services $(3,5-7,9,12)$, shops $(3$, 
$6-9,11,12)$ and offices $(6-9)$ but the number of functions proposed is often reduced during the process.

The most common type of dwellings in 7 cases $(1-5,7$ and 11$)$ is the " 3 and more bedrooms" dwelling. In case studies 6, 8 and 12, the main type of dwelling is the " 2 bedrooms" one. Studio and small apartments are not often developed in most of the case studies because the projects are mainly dedicated to families.

Last but not least, the 3 last criteria of the handbook are not often met in the cases studies and highlight a common trend in the development of (sustainable) urban projects: the lack of consideration for social aspects and community involvement. Dwellings accessible to low-income dwellings are mainly located in projects managed by public authorities $(2,11$ and 12$)$.

Finally, 6 case studies $(2,3,6,7,9$ and 12) met the minimum criteria to gain the "sustainable neighbourhood" label in Wallonia. Case studies 8 and 11 could easily met the minimum criteria if minor adjustments are made.

\section{Conclusions and perspectives}

A novel handbook that aims at facilitating the integration of cross-cutting criteria of sustainability into urban projects has been developed. This handbook is intended to help architects and private developers to build sustainable neighbourhood and local and regional authorities to assess urban projects, at the neighbourhood scale. This handbook, validated by the regional authority, constitutes a reference for the development of new (sustainable) neighbourhood in Wallonia (Belgium). The handbook was applied to 12 recent case studies in order to identify common invariants in the design process of "sustainable neighbourhoods" and barriers to the integration of cross-cutting principles of sustainability in neighbourhood projects. Our main results showed that the criteria dealing with energy performance of buildings and green spaces have percolated in many cases. However, announced performances are often reduced during the process, mainly because of economic constraints. Private developers and funders are also often afraid to develop urban projects too different from the traditional "residential neighbourhoods". Issues such as the management of parking places or the waste management are often difficult to meet in new urban projects because of the existence of local regulations that do not take sustainability into account. The diversity of dwellings, the accessibility to handicapped peoples, social diversity and participation issues remain poorly addressed in most of the cases studies. These issues, as well as the monitoring of the performances during the life of a neighbourhood, should be investigated in further research to be overpassed.

\section{Acknowledgements}

This research was funded by the Walloon Minister of Environment, Urban Planning and Mobility (Belgium). We thank C. Delbar, V. Loiseau and F. Godard for their help on the analysis and the local stakeholders that provided us with necessary information about the case studies. 


\section{References}

[1] The handbook: Teller, J., Marique, A.-F., Loiseau, V., Godard, F., Delbar, C. Référentiel Quartiers Durables (Guides méthodologiques), SPW DGO 4: Namur, 2014. Online: http://www.wallonie.be/fr/publications/quartiersdurables-mode-demploi.

[2] Emélianoff, C., Les quartiers durables en Europe: un tournant urbanistique? Urbia, 4, pp. 11-30, 2007.

[3] Souami, T., Ecoquartiers. Secrets de fabrication. Analyse critique d'exemples européens, Les carnets de l'info: Paris, 2009.

[4] Marique, A.-F., Reiter S., Towards more sustainable neighborhoods: are good practices reproducible and extensible? Proc. of the International Conference PLEA 2011, eds. M. Bodart \& A. Evrard, Presses Universitaires de Louvain: Louvain-La-Neuve, pp. 27-32, 2011.

[5] Da Cunha, A., Eco-quartiers et urbanisme durable: entre performance écologique et renforcement du lien social, Urbia, 4, pp. 1-10, 2007.

[6] Sharifi, A., Murayama, A., A critical review of seven selected neighbourhood sustainability assessment tools, Environmental Impact Assessment Review. 38, pp. 73-87, 2013.

[7] Charlot-Valdieu C., Outrequin P. (eds), Ecoquartier: mode d'emploi, Eyrolles: Paris, 2009.

[8] Jégou, A., About de Chastenet, C., Auguiseau, V., Guyot, C., Judéaux, C., Monaco, F.-X., Pech, P., L'évaluation par indicateurs: un outil nécessaire d'aménagement urbain durable?, Cybergeo: European Journal of Georgraphy (online), Aménagement, Urbanisme, article 625, 2012. URL: http://cybergeo.revues.org/25600; DOI: 10.400/cybergeo.25600, $(02 / 2014)$.

[9] STAR Community Rating System, version 1.0 (2012), https://www.starcommunities.org/uploads/rating-system.pdf (02/ 2014).

[10] LEED, http://www.usgbc.org/neighborhoods, 2014 (02/ 2014).

[11] BREEAM, http://www.breeam.org/page.jsp?id=372, 2014 (02/ 2014).

[12] HQE2R, http://www.suden.org/fr/projets-europeens/hqe2r/, 2014 (02/ 2014).

[13] CASBEE for Urban Development, Technical Manual 2007 edition, Institute for Building Environment and Energy Conservation, 2007.

[14] Halleux, J.-M., Vers la ville compacte qualitative? Gestion de la périurbanisation et actions publiques. Belgeo, 1-2, pp. 1-16, 2012.

[15] Marique, A.-F., Dujardin, S., Teller, J., Reiter, S., Urban sprawl, commuting and travel energy consumption. Proceedings of the Institution of Civil Engineers. Energy, 166(1), pp. 29-41, 2013. 